\title{
SNHS SUMMER MEETING, JUNE 13-15, 1969
}

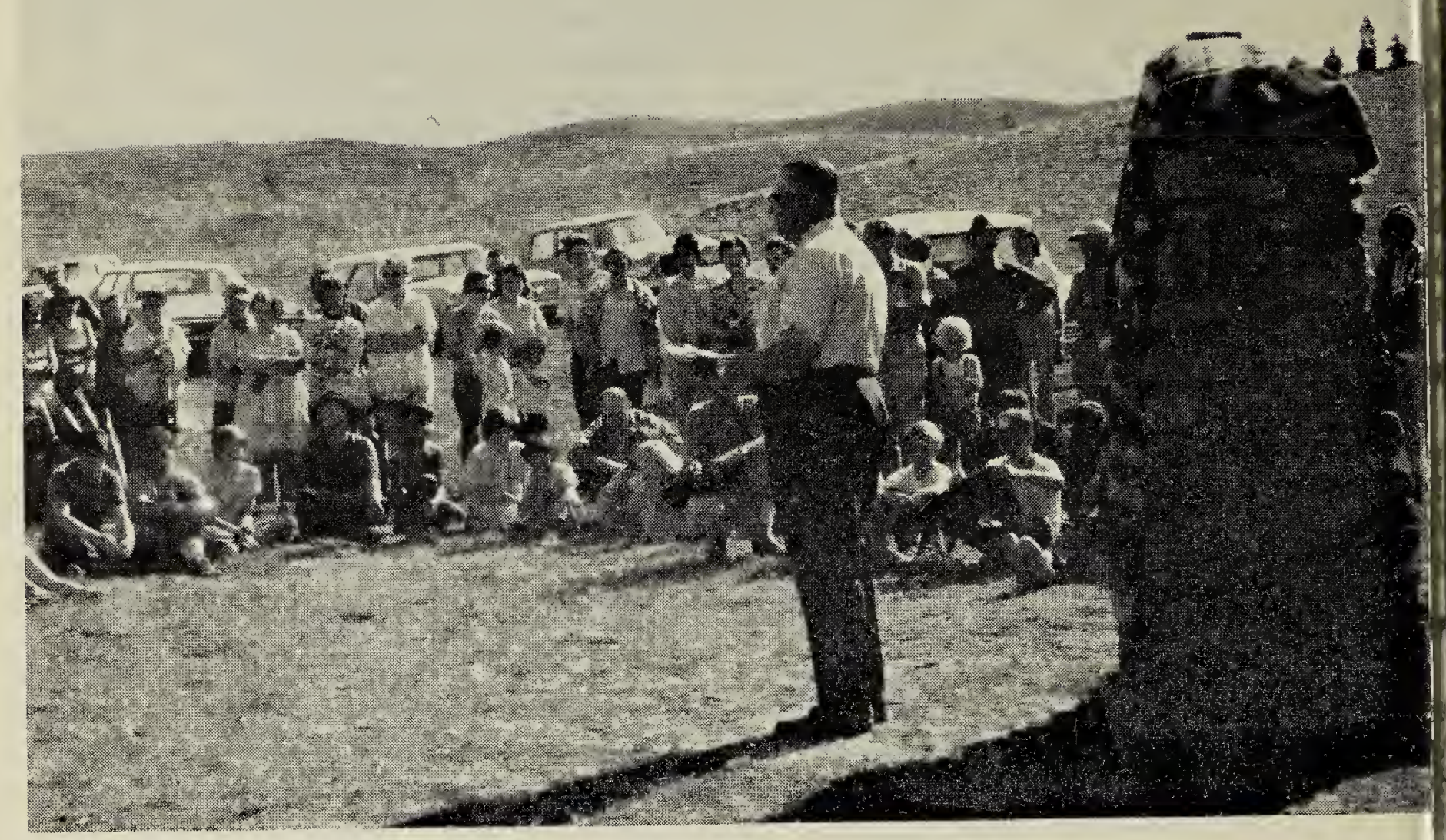

Mr. F. Larochelle, M.L.A. for Shaunavon, unveiling the cairn marking the Society's Prairie Dog Sanctuary, June 14, 1969.

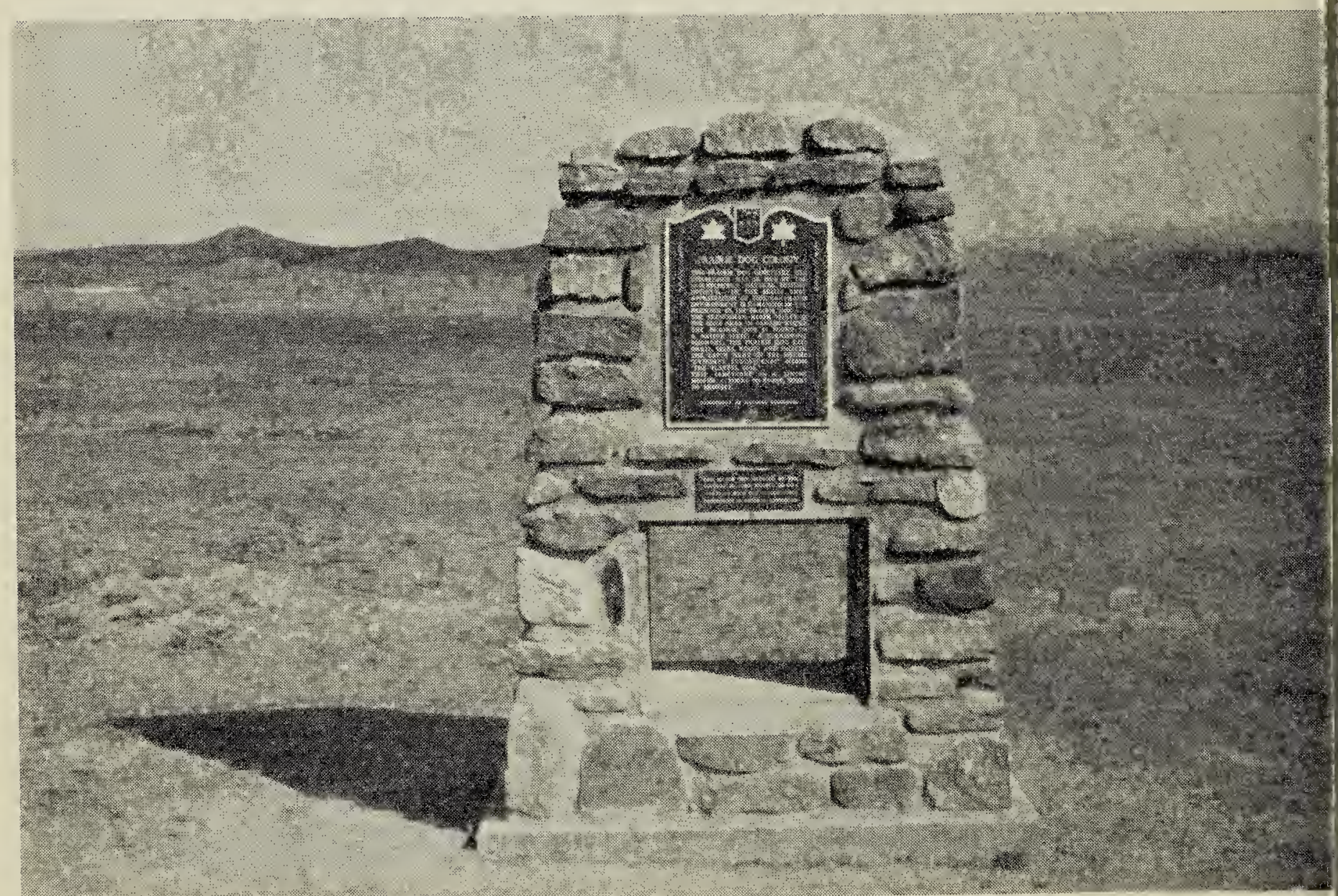

Photos by Gary Seil

The beautiful cairn of prairie stone raised by Ruth and David Chandler for the sanctuary. 